\title{
Interfaces in Cross-linked and Grafted Bacterial Cellulose/Poly(lactic acid) Resin Composites
}

\author{
Franck Quero and Stephen J. Eichhorn ${ }^{\mathrm{a}, \mathrm{b}^{*}}$ \\ ${ }^{a}$ Materials Science Centre, School of Materials, University of Manchester, Grosvenor Street, \\ Manchester, M13 9PL, UK. \\ ${ }^{\mathrm{b}}$ The Northwest Composite Centre, School of Materials, University of Manchester, Paper \\ Science Building, Sackville Street, Manchester, M13 9PL, UK.
}

Masaya $\mathrm{Nogi}^{\mathrm{c}}$

${ }^{\mathrm{c}}$ Institute of Science and Industrial Research, Osaka University, Mihogaoka 8-1, Ibaraki, Osaka, 567-0047, Japan.

Hiroyuki Yano ${ }^{\mathrm{d}}$

${ }^{\mathrm{d}}$ Research Institute for the Sustainable Humanosphere, Kyoto University, Uji, Kyoto 611-011, Japan.

Koon-Yang Lee and Alexander Bismarck ${ }^{\mathrm{e}}$

${ }^{\mathrm{e}}$ Polymer and Composites Engineering (PaCE) Group, Department of Chemical Engineering, Imperial College London, South Kensington Campus, London, SW7 2AZ, UK.

*Present Address: College of Engineering, Mathematics and Physical Sciences, Harrison Building, North Park Road, Exeter, UK, EX4 4QF.s.j.eichhorn@exeter.ac.uk

Telephone: +44 (0)1392 72 5515, Fax: +44 (0)1392 217965 


\begin{abstract}
This article presents approaches to maximize the mechanical performance of bacterial cellulose/poly(lactic acid) composites through chemical modification of the interface. This is achieved by both cross-linking the layered bacterial cellulose structure and by grafting to the matrix material. Unmodified and glyoxalized bacterial cellulose (BC) networks have been embedded in poly(lactic acid) (PLA) resin and then in maleated resin using a compression molding method. The effect of these chemical modifications on the physical properties of these composites is reported. The tensile properties of the composites showed that Young's moduli can be increased significantly when both BC networks and PLA were chemically modified. Interface consolidation between layers in BC networks has been achieved by glyoxylation. An improved interface between BC and PLA has been achieved by grafting polar maleic anhydride monomers along the backbone structure of PLA. The effect of these modifications on stress-transfer was quantified using Raman spectroscopy. Two competitive deformation mechanisms are identified; namely the mobility between BC layers, and between BC and PLA. The coupling strength of these interfaces could play a key role for optimization of these composites' mechanical properties.
\end{abstract}

Keywords Raman spectroscopy, stress-transfer, bacterial cellulose, interface, biocomposite 


\section{Introduction}

Currently, the industrial production of most polymers depends on petroleum resources. Consideration of other resources for the manufacturing of polymers will be need in the future as oil production decreases [1]. Materials obtained from renewable resources have been recently considered for producing polymers and polymer composites [2, 3]. In addition to being obtained from renewable resources, this class of materials commonly referred to as biopolymers, are generally biodegradable, which makes them attractive materials for the production of environmentally friendlier products.

Poly(lactic acid) (PLA) is considered a biopolymer that is synthesized by the ring opening polymerization of $L$-lactide, which is obtained from the fermentation of D-glucose derived from corn or other sugar containing feedstock [4]. PLA also has the advantage of being biodegradable under specific conditions [4]. This biopolymer has been specifically identified as a potential, and now commercial packaging material [5], but also as a matrix material for composite [6] and nanocomposite applications [7]. For instance, nanoclays [7], carbon nanotubes [8] and nanocelluloses [9] have been reported to mechanically reinforce PLA.

Cellulose is a natural polymer, and is mainly produced by plants, where it plays a structural role owing to its high stiffness [10]. Cellulose can also be extracted from sea animals (tunicates) [11], or produced bacteria from the Acetobacter species [12]. Cellulose is known to possess high mechanical properties and consequently has the potential to be used as a reinforcing agent in polymer materials [13]. A value of $138 \mathrm{GPa}$ for the elastic modulus of the cellulose I crystal has been measured using X-ray diffraction $[14,15]$. Young's modulus of bacterial cellulose (BC) 
nanofibrils has been determined using an AFM cantilever method [16] and by Raman spectroscopy [17]; values of $78 \pm 17$ and $114 \mathrm{GPa}$ were obtained, respectively. Consequently, BC nanofibres have great potential to be used as a reinfrocement for high stiffness, environmentally friendly composites and nanocomposites. As such, BC nanofibres have been used to reinforce polymers such as polyvinyl alcohol [18], acrylic resin [19] PLA [20-22] and cellulose acteate butyrate [23].

BC can either be cultured in static [24] or agitated conditions [25]. When cultured in static conditions, BC is produced in the form of very thin pellicles, which comprise a network of entangled nanofibrils. The Young's moduli of these pellicles in the dry state has been evaluated and values ranging from approximately 9 up to $30 \mathrm{GPa}$ have been obtained $[17,26,27]$. Therefore, BC pellicles have good potential as reinforcement for polymeric materials. Recently, BC/PLA composites have been made using a compression molding technique [28]. Transparent and opaque laminated composites were produced, depending on the culturing time used to produce the $\mathrm{BC}$ pellicles and therefore their thickness [28]. A culturing time of three days was found to favor the interaction between BC and PLA, compared to BC networks cultured for six days. Further optimization of the mechanical performance of these composites should still be possible since the various layers constituting these composites experience delamination when submitted to external tensile deformation. BC networks, constituted of weakly linked layers, have been subsequently cross-linked using glyoxal [29] in order to reduce delamination. The potential of these glyoxalised BC networks for composite reinforcement still requires evaluation. The aim of the present study is to verify if glyoxalisation of BC networks and/or maleation of PLA are potential routes for improving the mechanical performance of BC/PLA composites. The 
roles of two separate interfaces in these composites are thereby identified; the interfaces between layers within the $\mathrm{BC}$ networks themselves, and the interface between the networks and the matrix polymer.

\section{Experimental}

\section{Materials and chemicals}

BC networks were produced from Gluconacetobacter xylinum (no. 13693; National Institute of Technology and Evaluation, Tokyo, Japan) in Hestrin-Schramm (HS) medium [24, 30]. The cells for the inoculum were cultured in test tubes statically at $27{ }^{\circ} \mathrm{C}$ for 2 weeks. The thick gel produced during culturing was then squeezed aseptically to remove the embedded cells. The cell suspension $(25 \mathrm{ml})$ was then transferred as an inoculum for the main culture $(500 \mathrm{ml}$ of medium), which was incubated statically at $27^{\circ} \mathrm{C}$ for 14 days. $\mathrm{BC}$ networks ( $35 \mathrm{~mm}$ in diameter) were purified by boiling with $2 \% \mathrm{NaOH}$ for $2 \mathrm{~h}$, and then by washing with distilled water to neutral $\mathrm{pH}$, followed by hot pressing at $2 \mathrm{MPa}$ and $120{ }^{\circ} \mathrm{C}$ for 4 min to completely remove the bulk water. The density of these $\mathrm{BC}$ networks was estimated and found to be $\sim 1.1 \mathrm{~g} \mathrm{~cm}^{-3}$.

PLA L9000 was purchased from Biomer (Krailing, Germany). Glyoxal ( $40 \mathrm{wt} \%$ in de-ionised water), aluminium sulphate hexadecahydrate $\left(\mathrm{Al}_{2}\left(\mathrm{SO}_{4}\right)_{3} \cdot 16 \mathrm{H}_{2} \mathrm{O}\right.$, purity $\left.\geq 98 \%\right)$, maleic anhydride and dicumyl peroxide were purchased from Sigma-Aldrich (Gillingham, UK). 
BC networks were cut into strips and then glyoxalized as previously reported in the literature [29]. Briefly, an aqueous solution containing $40 \mathrm{wt} . \%$ of glyoxal was diluted to a $5 \mathrm{wt} . \%$. BC strips were immersed in that solution for 4 hours. After that, the strips were rinsed with deionised water and then cured at $150{ }^{\circ} \mathrm{C}$ for $15 \mathrm{~min}$ in a convection oven. They were then subsequently washed in de-ionised water at $70{ }^{\circ} \mathrm{C}$ for 1 hour. $\mathrm{BC}$ strips were finally dried at 110 ${ }^{\circ} \mathrm{C}$ overnight. These glyoxalized BC networks are referred as BCG. Unmodified BC networks are referred as $\mathrm{BC}$.

Preparation of maleated poly(lactic resin)

PLA pellets were dried at $40{ }^{\circ} \mathrm{C}$ for $24 \mathrm{~h}$ prior to extrusion. Maleated PLA (MAPLA) was formulated by first adding $2 \mathrm{wt} . \%$ of maleic anhydride (MA) relative to the PLA in the extruder and by then by adding $0.5 \mathrm{wt} . \%$ of dicumyl peroxide (DiP) realtive to the weight of MA. Haake miniCTW micro compounder (Thermo Scientific) was used (100 rpm for $3 \mathrm{~min}$ at $\left.180{ }^{\circ} \mathrm{C}\right)$ to produce MAPLA. MAPLA compounds were finally cut into pellets manually.

\section{Preparation of composites}

PLA and MAPLA pellets were dried at $40{ }^{\circ} \mathrm{C}$ for at least $24 \mathrm{~h}$ prior to film preparation. The pellets were melted at $180{ }^{\circ} \mathrm{C}$ for $120 \mathrm{~s}$ and then compressed at $12 \mathrm{MPa}$ for $120 \mathrm{~s}$ in a steel mould. After that, the mould was cooled for $150 \mathrm{~s}$. This procedure produced transparent PLA and MAPLA films. BC/PLA, BCG/PLA, BC/MAPLA and BCG/MAPLA composites were prepared by compressing BC and BCG strips between two PLA or MAPLA films, under the same processing conditions. The $\mathrm{BC}$ volume fractions for $\mathrm{BC} / \mathrm{PLA}, \mathrm{BCG} / \mathrm{PLA}, \mathrm{BC} / \mathrm{MAPLA}$ and 
BCG/MAPLA were respectively $13.8 \pm 3.2,12.3 \pm 1.2,13.9 \pm 1.2$ and $15.5 \pm 2.1$ vol.\%. The volume fractions of these nanocomposites are within the error bounds of each other and so no significant variations are noted between composite samples.

${ }^{1} H$ NMR and gel permeation chromatography (GPC)

${ }^{1} \mathrm{H}$ NMR analysis was performed using a Bruker AV500 instrument; spectra were collected at $500 \mathrm{MHz} . \mathrm{CDCl}_{3}$ was used as the NMR solvent and reference compound. The GPC measurements were carried out on both processed PLA and MAPLA films using a Polymer Laboratories SEC 50 instrument with two Polymer Laboratories mixed D columns and $\mathrm{CHCl}_{3}$, at a flow rate of $1 \mathrm{ml} \mathrm{min}{ }^{-1}$, as the eluent. Narrow molecular weight polystyrene standards (Polymer laboratories, mixed A and B) were used to calibrate the instrument.

Thermogravimetric analysis (TGA)

The thermal degradation behavior of all materials was investigated using thermogravimetric analysis (TGA Q500). The samples (approximately $4 \mathrm{mg}$ ) were heated from room temperature up to $600{ }^{\circ} \mathrm{C}$ using a heating rate and nitrogen purge flow of $5{ }^{\circ} \mathrm{C} \mathrm{min}{ }^{-1}$ and $60 \mathrm{ml} \mathrm{min}{ }^{-1}$, respectievely. The onset and peak degradation temperatures were obtained from the first derivative of the weight loss as a function of temperature. The temperature control in the furnace is $\pm 1{ }^{\circ} \mathrm{C}$. Experiments were repeated in triplicate to ensure repeatability.

\section{Tensile properties}


The tensile properties of PLA, MAPLA and BC/PLA, BCG/PLA, BC/MAPLA, BCG/MAPLA composites were determined using a tensile testing machine (Instron 2511-111, High Wycombe, UK). The full-scale load and the crosshead speed used were $50 \mathrm{~N}$ and $0.5 \mathrm{~mm} \mathrm{~min}^{-1}$, respectively. The machine compliance was determined and found to be $4.4 \times 10^{-3} \mathrm{~mm} \mathrm{~N}^{-1}$. Composite specimens $(\sim 20 \mathrm{~mm} \times 1 \mathrm{~mm} \times 0.2 \mathrm{~mm})$ were secured onto $20 \mathrm{~mm}$ gauge length testing cards using a two-part cold curing epoxy resin (Araldite ${ }^{\circledR}$ ). Mechanical test was conducted at $23 \pm 1{ }^{\circ} \mathrm{C}$ and a relative humidity of $50 \pm 0.5 \%$. The samples were pre-conditioned under the same environmental conditions for $24 \mathrm{~h}$ prior to testing. A total of 6 samples were tested for each material. Sample widths and thicknesses were measured using an optical microscope and a micrometer, respectively, in order to calculate the cross sectional area (width $\times$ thickness) and ultimately the engineering stress.

\section{Scanning electron microscopy}

The fracture surfaces of the composites were observed using a scanning electron microscope (Phillips XL-30 FEG-SEM). An acceleration voltage of $5 \mathrm{kV}$ was used. Prior to SEM imaging, the samples were fixed onto metal stubs using carbon tabs and gold coated using an operating current of $40 \mathrm{~mA}$ for $2 \mathrm{~min}$.

\section{Raman spectroscopy}

The molecular deformation of BC/PLA and BCG/PLA composites was followed using a Raman spectrometer (Renishaw system-1000, Wotton-under-Edge, UK) coupled with an optical microscope and a near infra-red laser $(785 \mathrm{~nm})$. The laser was focussed to a $\sim 1-2 \mu \mathrm{m}$ spot using a $\times 50$ magnification long working distance lens. Composites were mounted on paper testing 
cards using a two-part cold-curing epoxy resin (Araldite ${ }^{\circledR}$, Huntsman, UK) and then deformed in tension using a customized deformation rig (Deben Microtest, Deben, Bury St Edmonds, UK). The compliance of the deformation rig was determined to be $3.1 \times 10^{-4} \mathrm{~mm} \mathrm{~N}^{-1}$. The gauge length of the samples and the full scale of the load cell used were $20 \mathrm{~mm}$ and $2 \mathrm{kN}$ respectively. During the deformation, the strain was increased incrementally by $0.05 \%$ at an elongation rate of 0.033 $\mathrm{mm} \mathrm{min}^{-1}$ between these steps. A Raman spectrum was recorded at each strain increment using an exposure time of $30 \mathrm{~s}$ and 4 accumulations. The peak positions of the Raman band initially located at $\sim 1095 \mathrm{~cm}^{-1}$ were determined by curve fitting with a mixed Gaussian/Lorentzian function, and by using an algorithm based on the work of Marquardt [31]. Experiments were repeated 2 times for each composite material.

\section{Results}

\section{Determination of the molecular weight of PLA and MAPLA}

Figure 1 illustrates the chemical grafting reaction of maleic anhydride along the PLA backbone structure in the presence of dicumyl peroxide [32]. This reaction has been already described in detail in the literature, and is referred to as a free radical branching reaction $[33,34]$.

Number-average $\left(M_{\mathrm{n}}\right)$ and weight-average $\left(M_{\mathrm{w}}\right)$ molecular weights and degree of polydispersity $\left(\mathrm{DP}=M_{\mathrm{w}} / M_{\mathrm{n}}\right)$ for PLA and MAPLA are reported in Table I. $M_{\mathrm{n}}$ and $M_{\mathrm{w}}$ of MAPLA are reduced by half, compared to pure PLA. These changes are the result of possible chemical and thermal degradation reactions due to the presence of free radicals, which induce polymer chain scissions of PLA during the extrusion reaction. 


\section{Determination of the amount of grafted maleic anhydride}

Figure 2 reports ${ }^{1} \mathrm{H}-\mathrm{NMR}$ spectra for PLA and MAPLA. The NMR trace for MAPLA shows a peak positioned at $\sim 2.7 \mathrm{ppm}$. This peak has been reported to correspond to the formation of succinyl anhydride group formation [35-37]. Two other peaks can be seen at approximately 7 and $6.5 \mathrm{ppm}$. They are thought to be due to the presence of unreacted maleic anhydride [38]. As expected, the NMR trace for PLA does not exhibit any of these peaks.

The grafting efficiency of maleic anhydride on the backbone structure of PLA was determined and found to be approximately $1.6 \mathrm{~mol} \%$ corresponding to $2.2 \mathrm{wt} . \%$.

\section{Thermal degradation}

Figure 3 reports typical TGA traces for PLA and MAPLA films and BC/PLA, BCG/PLA, BC/MAPLA and BCG/MAPLA composites. The onset and peak degradation temperatures and percentage of residual mass at $500{ }^{\circ} \mathrm{C}$ are shown in Table II. The onset degradation temperature of MAPLA is significantly lower than for PLA. This may be attributed to the reduced molecular weight of MAPLA compared to PLA which may reduce thermal stability. The peak degradation temperature and percentage of residual mass are, however, not significantly changed.

BC/PLA and BCG/PLA composites do not show any significant differences in thermal behavior. The onset and peak degradation temperatures of the BC/MAPLA and BCG/MAPLA composites are, however, significantly lower than BC/PLA and BCG/PLA. In addition, BCG/MAPLA composites have significantly lower onset and peak degradation temperatures than BC/MAPLA composites. This may be attributed to the significantly lower thermal stability of both BCG and 
MAPLA compared to BC and PLA. All composites were found to have a significantly higher percentage of residual mass at $500{ }^{\circ} \mathrm{C}$ compared to PLA and MAPLA. This shows that the presence of $\mathrm{BC}$ and $\mathrm{BCG}$ enhances the thermal stability of PLA and MAPLA at $500{ }^{\circ} \mathrm{C}$.

\section{Tensile mechanical properties}

Figure 4 reports typical stress-strain curves for PLA and MAPLA films and BC/PLA, BCG/PLA, BC/MAPLA and BCG/MAPLA composites. The mechanical properties of these materials are reported in Table III. A small but significant reduction in Young's modulus is noted after maleation of PLA has been performed. This may be also attributed to the reduced molecular weight of MAPLA compared to PLA. The stress at failure of MAPLA is, however, similar (within the error margins) to PLA. With the addition of BC, both Young's modulus and stress at failure increase significantly, due to the reinforcing effect of the cellulose fibrils. The strain at failure of the composite samples is reduced as a result of embrittlement of the polymer due to the presence of the stiff $\mathrm{BC}$ fibrils. The tensile stress, strain-to-failure and the work of fracture of the composites however, is reduced significantly when BCG or MAPLA are used. The Young's modulus of BCG/MAPLA composites is significantly increased when BC and PLA are respectively modified with glyoxal and maleic anhydride. This is even clearer when Young's moduli values of the composites are normalized by their respective matrices' Young's moduli $\left(E_{\mathrm{c}} / E_{\mathrm{m}}\right.$ in Table II). A further indication of this is that the experimental value for Young's modulus of BCG/MAPLA composites is much closer to the theoretical estimate obtained using the rule of mixtures, compared to values obtained for BC/PLA, BCG/PLA and BC/MAPLA composites. 
Morphology of tensile fracture surfaces

Figures 5a-d show the tensile fracture surfaces of BC/PLA, BCG/PLA, BC/MAPLA and BCG/MAPLA composites, respectively. Delamination can be seen occuring between BC layers, rather than at the BC/PLA interface (see figure 5a). This may explain why these composites have higher stress and strain at failure and work of fracture compared to BCG/PLA, BC/MAPLA and BCG/MAPLA composites. Additional strain to failure leading to greater energy dissipation is likely, due to the delamination observed. Figure $5 \mathrm{~b}$ shows that delamination mainly occurs at the BCG/PLA interface when cross-linked BC networks are used. A lack of delamination between glyoxalised BC layers is noted for this sample. It is possible that the bond strength between glyoxalised BC layers is stronger than that between the glyoxalised BC and the PLA resin. This may also explain why the work of fracture of BCG/PLA composites is lower than BC/PLA composites. Less energy is likely to be dissipated due to the presence of chemical cross-links between these layers, thereby reducing delamination.

Figure $5 \mathrm{c}$ shows the morphology of the tensile fracture surface of BC/MAPLA composites. A large central delamination between two BC layers is also observed. The interface between the $\mathrm{BC}$ and the MAPLA resin remains intact. This intact interface is thought to be due to the grafting of the resin to the BC. Figure 5d reports a similar image, but this time for BCG/MAPLA composites. The BCG/MAPLA interface again remains intact. Some delamination between glyoxalised BC layers is still observed, but not to the same extent as in Figures 5a and 5c. This may explain why BCG/MAPLA composites have significantly higher relative Young's modulus compared to BC/PLA, BCG/PLA and BC/MAPLA composites. This increase in modulus, closer 
to the theoretical value predicted by the rule of mixtures, reflects a reduction of mobility between BCG layers, and between BCG and MAPLA at the interface.

\section{Molecular deformation using Raman spectroscopy}

Figure 6a reports typical Raman spectra for PLA and MAPLA films and BC/PLA, BCG/PLA, BC/MAPLA and BCG/MAPLA composites in the range $300-1600 \mathrm{~cm}^{-1}$. The Raman band located at $\sim 1095 \mathrm{~cm}^{-1}$, attributed to the presence of cellulose, is observed for all composite materials. This means that it is possible to detect the presence of BC within the PLA and MAPLA resins. The Raman band located at $\sim 1095 \mathrm{~cm}^{-1}$ has been reported to correspond to vibrational motions of $\mathrm{C}-\mathrm{O}$ and $\mathrm{C}-\mathrm{O}-\mathrm{C}$ moieties present along the backbone structure of cellulose [39-41]. Figure 6b reports a typical shift towards a lower wavenumber position for the Raman band initially located at $\sim 1095 \mathrm{~cm}^{-1}$ for a BC/MAPLA composite. This Raman band has been found to shift towards a lower wavenumber under the application of external tensile deformation due to changes in interatomic distances between atoms within C-O-C and C-O moieties [42-45]. Similar shifts towards a lower wavenumber are observed for BC/PLA, BCG/PLA and BCG/MAPLA composites. Figure 7a reports detailed Raman band shifts for BC/PLA and BCG/PLA composites as a function of strain. Experimental data were fitted using a linear equation. The slope of this equation is used to quantify the stress-transfer or molecular deformation, as has been previously reported [28]. The higher the slope of this fit, the more efficient the stress-transfer from the matrix to the reinforcement [28]. Slopes of $-0.6 \pm 0.1$ and $0.6 \pm 0.1 \mathrm{~cm}^{-1} \%$ were obtained for respectively BC/PLA and BCG/PLA composites. It appears then that cross-linking BC layers with glyoxal does not significantly improve the stress-transfer efficiency of these composites. This may be because although BC layers are consolidated via 
chemical cross-linking, the stress-transfer efficiency is lost at the BCG/PLA interface. This loss of efficiency could be due to delamination, as shown in Figure 5b.

Figure $7 \mathrm{~b}$ reports detailed shifts in the position of the Raman band initially positioned at $\sim 1095$ $\mathrm{cm}^{-1}$ as a function of strain for BC/MAPLA and BCG/MAPLA composites. Slopes of $-1.2 \pm 0.3$ and $-1.3 \pm 0.3 \mathrm{~cm}^{-1} \%^{-1}$ were obtained for BC/MAPLA and BCG/MAPLA composites, respectively. These values are significantly higher than that for BC/PLA and BCG/PLA composites. This means that grafting polar maleic anhydride monomers along the PLA backbone enhances stress-transfer at the interface between MAPLA and both BC and BCG. In other words, the molecular mobility at the interface is reduced when using MAPLA instead of PLA, in agreement with previous studies on plant fibres and PLA [46]. No significant difference is, however, noted between BC/MAPLA and BCG/MAPLA composites. This may be because the Raman technique only enables detection of molecular deformation at the surface of the $\mathrm{BC}$, close to the BC/MAPLA interface, and not within the bulk of the material. Large delamination events occurring far away from the interface (see Figure 5c) may not therefore be detected.

\section{Discussion}

It is thought that two main interfaces are critical to the mechanical properties of bacterial cellulose-polymer composites; namely that between weakly bound layers between stacked fibrillar networks of $\mathrm{BC}$ and between the upper faces of the networks and the resin. Due to the density of the networks, it is thought that little resin penetration occurs into the bulk of the BC material [28]. This means that these two interfaces, unless modified, could lead to reduced stress-

transfer in a composite. Figures $8 \mathrm{a}$ and $8 \mathrm{~b}$ illustrate potential deformation mechanisms in 
respectively BC/PLA and BCG/PLA and BC/MAPLA and BCG/MAPLA composite materials. As already stated, the deformation process experienced in these composites seems to be governed by two competitive mechanisms; delamination between $\mathrm{BC}$ layers and delamination at the $\mathrm{BC} /$ polymer interface. In BC/PLA composites, delamination seems to preferably occur between $\mathrm{BC}$ layers. This is possibly due to the stronger interaction between BC and PLA compared to the interaction between BC layers. The latter have been reported to be weakly linked. In BCG/PLA composites, delamination is likely to occur at the BCG/PLA interface rather than between glyoxalised BC layers. Owing to the presence of chemical cross-links, the bonding strength between BC layers may be stronger than the bonding strength between BCG and PLA. In the same way as for BC/PLA composites, delamination in BC/MAPLA composites probably occurs between BC layers. The bonding strength between BC and MAPLA may, in this case, be stronger than the bonding strength between BC and PLA. This hypothesis is what the Raman spectroscopic data suggest, with a higher molecular deformation measured for BC/MAPLA composites $\left(-1.2 \pm 0.3 \mathrm{~cm}^{-1} \%^{-1}\right)$ compared to BC/PLA composites $\left(-0.6 \pm 0.1 \mathrm{~cm}^{-1} \%^{-1}\right)$. In BCG/MAPLA composites, the delamination process between glyoxalised BC layers is reduced, but in addition the BCG/MAPLA interface is also consolidated. Some delamination between glyoxalised BC layers is, however, still observed, which possibly reduces stress-transfer. Nevertheless, only these composites show values of Young's modulus close to the theoretical limit predicted by the rule of mixtures, which suggests that these routes for interface improvement could be used to further optimize mechanical properties.

\section{Conclusions}

Biocomposites have been prepared by compressing unmodified and glyoxalised BC networks inbetween two PLA films. Similar materials have also been prepared using maleated PLA 
(MAPLA). The molecular weight of PLA and MAPLA has been determined using GPC. The results revealed that the molecular weight of PLA was reduced by half after reactive extrusion in the presence of MA and DiP. $\mathrm{H}^{1}$ NMR was then used to determine the amount of maleic anhydride grafted along the PLA backbone structure. A grafting efficiency of 2.2 wt.\% was obtained. The thermal degradation properties of PLA and MAPLA films and composites have been investigated using TGA. A significant increase in the thermal stability of the composites was observed at $500{ }^{\circ} \mathrm{C}$. The onset and degradation temperatures of BCG/MAPLA composites were found to be significantly lower than all other composites. Tensile mechanical properties of the composites revealed that in order to significantly increase relative Young's modulus of this form of composite, both BC networks and PLA have to be chemically modified. The tensile fracture surfaces revealed that the layered structure of these composites can be consolidated by first chemical cross-linking of $\mathrm{BC}$ layers and then by chemical compatibilisation of the interface. Raman spectroscopy was subsequently used to quantify the stress-transfer from the matrix to the reinforcement. This revealed that the molecular deformation can be significantly increased when using MAPLA as a matrix instead of PLA, by increasing stress-transfer between the matrix and the reinforcing phase. No significant difference in the stress transfer efficiency was, however, observed when comparing BC/MAPLA and BCG/MAPLA composites. Two competitive deformation mechanisms have been identified from the characterization of these composites; namely the bonding strength between $\mathrm{BC}$ layers and the interface between $\mathrm{BC}$ and the polymer matrix. Maximization of the mechanical performance could be possible when the bonding strength of the interfaces between $\mathrm{BC}$ layers and between the $\mathrm{BC}$ and the matrix are equal.

\section{Acknowledgments}


Two authors (FQ and SJE) would like to thank the EPSRC for funding a PhD studentship (to FQ) under Grant GR/F028946.

\section{References}

1. $\quad$ S.J. Eichhorn and A. Gandini, MRS Bull. 35 (2010) 187.

2. S.J. Eichhorn, A. Dufresne, M. Aranguren, N.E. Marcovich, J.R. Capadona, S.J. Rowan, C. Weder, W. Thielemans, M. Roman, S. Renneckar, W. Gindl, S. Veigel, J. Keckes, H. Yano, K. Abe, M. Nogi, A.N. Nakagaito, A. Mangalam, J. Simonsen, A.S. Benight, A. Bismarck, L.A. Berglund, and T. Peijs, Journal of Materials Science. 45 (2010) 1.

3. A. Gandini, Macromolecules. 41 (2008) 9491.

4. $\quad$ R.H. Platel, L.M. Hodgson, and C.K. Williams, Polym. Rev. 48 (2008) 11.

5. R. Auras, B. Harte, and S. Selke, Macromolecular Bioscience. 4 (2004) 835.

6. K. Oksman, M. Skrifvars, and J.F. Selin, Composites Science and Technology. 63 (2003) 1317.

7. $\quad$ S.S. Ray and M. Okamoto, Macromol. Rapid Commun. 24 (2003) 815.

8. K.K. Yang, X.L. Wang, and Y.Z. Wang, J. Ind. Eng. Chem. 13 (2007) 485.

9. K. Oksman, A.P. Mathew, D. Bondeson, and I. Kvien, Composites Science and Technology. 66 (2006) 2776.

10. A.C. O'Sullivan, Cellulose. 4 (1997) 173.

11. B.G. Ranby, Ark Kemi. 4 (1952) 241.

12. A.J. Brown, Journal of the Chemical Society. 49 (1886) 432.

13. S.J. Eichhorn, C.A. Baillie, N. Zafeiropoulos, L.Y. Mwaikambo, M.P. Ansell, A. Dufresne, K.M. Entwistle, P.J. Herrera-Franco, G.C. Escamilla, L. Groom, M. Hughes, C. Hill, T.G. Rials, and P.M. Wild, Journal of Materials Science. 36 (2001) 2107.

14. T. Nishino, K. Takano, and K. Nakamae, Journal of Polymer Science Part B: Polymer Physics. 33 (1995) 1647.

15. I. Sakurada, Y. Nukushina, and T. Ito, Journal of Polymer Science. 57 (1962) 651.

16. G. Guhados, W. Wan, and J.L. Hutter, Langmuir. 21 (2005) 6642.

17. Y.C. Hsieh, H. Yano, M. Nogi, and S. Eichhorn, Cellulose. 15 (2008) 507.

18. S. Gea, E. Bilotti, C.T. Reynolds, N. Soykeabkeaw, and T. Peijs, Materials Letters. 64 (2010) 901.

19. H. Yano, J. Sugiyama, A.N. Nakagaito, M. Nogi, T. Matsuura, M. Hikita, and K. Handa, Advanced Materials. 17 (2005) 153.

20. K.-Y. Lee, J.J. Blaker, and A. Bismarck, Composites Science and Technology. 69 (2009) 2724.

21. Y. Kim, R. Jung, H.-S. Kim, and H.-J. Jin, Current Applied Physics. 9 (2009) S69.

22. Z.Q. Li, X.D. Zhou, and C.H. Pei, Polymer-Plastics Technology and Engineering. 49 (2010) 141.

23. W. Gindl and J. Keckes, Composites Science and Technology. 64 (2004) 2407.

24. M. Schramm and S. Hestrin, Journal of General Microbiology. 11 (1954) 123.

25. K. Watanabe, M. Tabuchi, Y. Morinaga, and F. Yoshinaga, Cellulose. 5 (1998) 187. 
26. S. Yamanaka, K. Watanabe, N. Kitamura, M. Iguchi, S. Mitsuhashi, Y. Nishi, and M. Uryu, Journal of Materials Science. 24 (1989) 3141.

27. S. Gea, C.T. Reynolds, N. Roohpour, B. Wirjosentono, N. Soykeabkaew, E. Bilotti, and T. Peijs, Bioresource Technology. 102 (2011) 9105.

28. F. Quero, M. Nogi, H. Yano, K. Abdulsalami, S.M. Holmes, B.H. Sakakini, and S.J. Eichhorn, ACS Applied Materials \& Interfaces. 2 (2009) 321.

29. F. Quero, M. Nogi, K.-Y. Lee, G.V. Poel, A. Bismarck, A. Mantalaris, H. Yano, and S.J. Eichhorn, ACS Applied Materials \& Interfaces. 3 (2010) 490.

30. S. Hestrin and M. Schramm, Biochemical Journal. 58 (1954) 345.

31. D.W. Marquardt, SIAM Journal on Applied Mathematics. 11 (1963) 431.

32. C. Nyambo, A.K. Mohanty, and M. Misra, Macromolecular Materials and Engineering. 296 (2011) 710.

33. D. Carlson, P. Dubois, L. Nie, and R. Narayan, Polymer Engineering \& Science. 38 (1998) 311.

34. D. Carlson, L. Nie, R. Narayan, and P. Dubois, Journal of Applied Polymer Science. 72 (1999) 477.

35. M.R. Thompson, C. Tzoganakis, and G.L. Rempel, Polymer. 39 (1998) 327.

36. M.R. Thompson, C. Tzoganakis, and G.L. Rempel, Journal of Applied Polymer Science. 71 (1999) 503.

37. A. Vicente, S. Pereira, T. Nunes, and M. Ribeiro, Journal of Polymer Research. 18 (2011) 527.

38. E. Pretsch, P. Bühlmann, and C. Affolter, Structure determination of organic compounds. 2000, Berlin: Springer-Verlag.

39. J.H. Wiley and R.H. Atalla, Carbohydrate Research. 160 (1987) 113.

40. N. Gierlinger, M. Schwanninger, A. Reinecke, and I. Burgert, Biomacromolecules. 7 (2006) 2077.

41. H.G.M. Edwards, D.W. Farwell, and D. Webster, Spectrochimica Acta Part A: Molecular and Biomolecular Spectroscopy. 53 (1997) 2383.

42. R. Rusli and S.J. Eichhorn, Applied Physics Letters. 93 (2008) 033111.

43. A. Šturcová, G.R. Davies, and S.J. Eichhorn, Biomacromolecules. 6 (2005) 1055.

44. S.J. Eichhorn, J. Sirichaisit, and R.J. Young, Journal of Materials Science. 36 (2001) 3129.

45. S.J. Eichhorn and R.J. Young, Composites Science and Technology. 63 (2003) 1225.

46. M.S. Huda, L.T. Drzal, M. Misra, and A.K. Mohanty, Journal of Applied Polymer Science. 102 (2006) 4856. 


\section{LIST OF TABLES}

Table I Gas permeation chromatography measurements for PLA and MAPLA. $M_{\mathrm{n}}$ is the number-average molecular weight, $M_{\mathrm{w}}$ is the weight-average molecular weight and $P D$ is the degree of polydispersity.

Table II Thermal properties for PLA, MAPLA, BC/PLA, BCG/PLA, BC/MPLA, BCG/MPLA materials. Error bars are standard deviations from the mean for 3 samples.

Table III Tensile mechanical properties for PLA, BC/PLA, BCG/PLA, BC/MPLA, BCG/MPLA composites. Error bars are standard deviations from the mean for 6 samples. NA stands for not applicable. 


\section{LIST OF FIGURES}

Figure 1 Chemical reactions occurring during extrusion of PLA in the presence of maleic anhydride and dicumyl peroxide.

Figure 2 Typical $\mathrm{H}^{1}$ NMR spectra for PLA and MAPLA.

Figure 3 Typical thermal degradation profiles for PLA, MAPLA, BC/PLA, BCG/PLA, BC/MAPLA and BCG/MAPLA materials.

Figure 4 Typical stress-strain curves for PLA, MAPLA, BC/PLA, BCG/PLA, BC/MAPLA, BCG/MAPLA materials.

Figure 5 Scanning electron microscope images of tensile fracture surfaces for (a) BC/PLA, (b) BCG/PLA, (c) BC/MAPLA and (d) BCG/MAPLA composites.

Figure 6 (a) Typical Raman spectra for PLA, MAPLA and BC/PLA and BC/MAPLA; (b) Typical shifts in the position of the Raman band initially located at $\sim 1095 \mathrm{~cm}^{-1}$ towards a lower wavenumber for BC/PLA and BC/MAPLA. Percentage values correspond to the level of tensile deformation.

Figure 7 Detailed typical shifts in the position of the Raman band located at $\sim 1095 \mathrm{~cm}^{-1}$ for (a) BC/PLA (b) BCG/PLA (c) BC/MAPLA and (d) BCG/MAPLA composites. Data represent two repeats for each material.

Figure 8 Proposed deformation mechanisms for (a) BC/PLA and BCG/PLA and (b) BC/MAPLA and BCG/MAPLA composites. Arrows represent the external forces applied to the composite materials. 


\begin{tabular}{cccc}
\hline & $\mathrm{M}_{\mathrm{n}}\left(\mathrm{g} \mathrm{mol}^{-1}\right)$ & $\mathrm{M}_{\mathrm{w}}\left(\mathrm{g} \mathrm{mol}^{-1}\right)$ & $\mathrm{PD}$ \\
\hline PLA & 160000 & 212000 & 1.3 \\
MAPLA & 73000 & 122000 & 1.7 \\
\hline
\end{tabular}

\section{Table I}

\begin{tabular}{cccc}
\hline Material & $\begin{array}{c}\text { Onset degradation } \\
\text { temperature }\left({ }^{\circ} \mathrm{C}\right)\end{array}$ & $\begin{array}{c}\text { Peak degradation } \\
\text { temperature }\left({ }^{\circ} \mathrm{C}\right)\end{array}$ & $\begin{array}{c}\text { Percentage residual } \\
\text { mass at } 500^{\circ} \mathrm{C}(\%)\end{array}$ \\
\hline PLA & $317 \pm 1$ & $346 \pm 2$ & $-0.2 \pm 0.1$ \\
MAPLA & $313 \pm 2$ & $345 \pm 1$ & $-0.1 \pm 0.1$ \\
BC/PLA & $309 \pm 5$ & $343 \pm 8$ & $3.5 \pm 0.6$ \\
BCG/PLA & $309 \pm 4$ & $345 \pm 4$ & $3.5 \pm 0.8$ \\
BC/MAPLA & $303 \pm 1$ & $336 \pm 1$ & $2.0 \pm 0.4$ \\
BCG/MAPLA & $292 \pm 1$ & $326 \pm 2$ & $2.7 \pm 0.3$ \\
\hline
\end{tabular}

Table II

\begin{tabular}{ccccccc}
\hline $\begin{array}{c}\text { Material } \\
(\mathrm{BC} \text { volume } \\
\text { fraction \% })\end{array}$ & $\mathrm{E}(\mathrm{GPa})$ & $\mathrm{E}_{\mathrm{c}} / \mathrm{E}_{\mathrm{m}}$ & $\begin{array}{c}\mathrm{E}_{\text {predicted }} \\
(\mathrm{GPa})\end{array}$ & $\sigma_{\mathrm{f}}(\mathrm{MPa})$ & $\varepsilon_{\mathrm{f}}(\%)$ & $\mathrm{G}\left(\mathrm{MJ} \mathrm{m}^{-3}\right)$ \\
\hline PLA & $2.0 \pm 0.2$ & $\mathrm{NA}$ & $\mathrm{NA}$ & $27.7 \pm 2.5$ & $23.5 \pm 17$ & ----- \\
MAPLA & $1.6 \pm 0.2$ & $\mathrm{NA}$ & $\mathrm{NA}$ & $33.9 \pm 3.4$ & $1.6 \pm 0.2$ & ---- \\
$\begin{array}{c}\mathrm{BC} / \mathrm{PLA} \\
(13.8 \pm 3.2)\end{array}$ & $2.7 \pm 0.3$ & 1.4 & 3.1 & $65.9 \pm 2.3$ & $3.0 \pm 0.5$ & $1.1 \pm 0.3$ \\
$\begin{array}{c}\text { BCG/PLA } \\
(12.3 \pm 1.2)\end{array}$ & $2.5 \pm 0.1$ & 1.3 & 3.1 & $55.9 \pm 4.5$ & $2.4 \pm 0.2$ & $0.7 \pm 0.1$ \\
$\begin{array}{c}\text { BC/MAPLA } \\
(13.9 \pm 1.2)\end{array}$ & $2.7 \pm 0.2$ & 1.7 & 3.1 & $32.2 \pm 5.4$ & $1.2 \pm 0.2$ & $0.2 \pm 0.1$ \\
$\begin{array}{c}\text { BCG/MAPLA } \\
(15.5 \pm 2.1)\end{array}$ & $3.2 \pm 0.2$ & 2 & 3.3 & $39.0 \pm 9.3$ & $1.4 \pm 0.2$ & $0.1 \pm 0.1$ \\
\hline
\end{tabular}

\section{Table III}




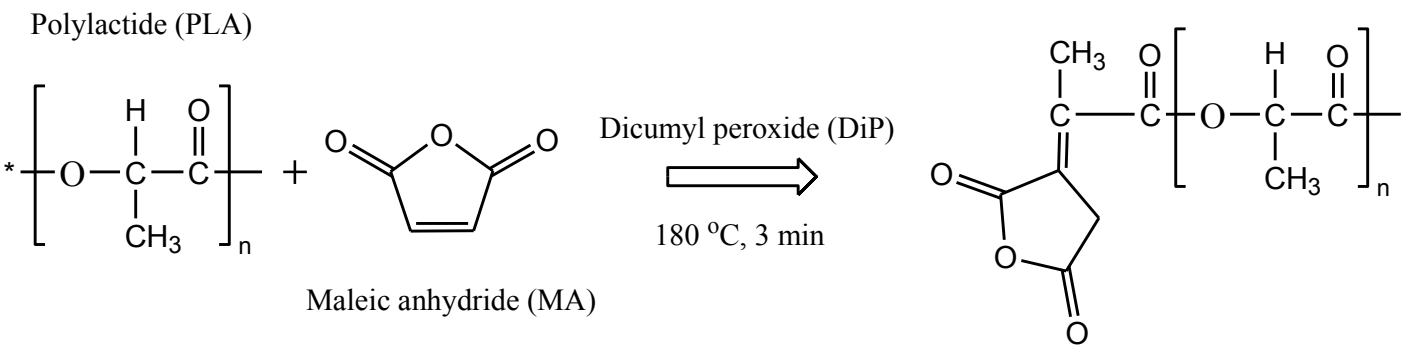

Figure 1 


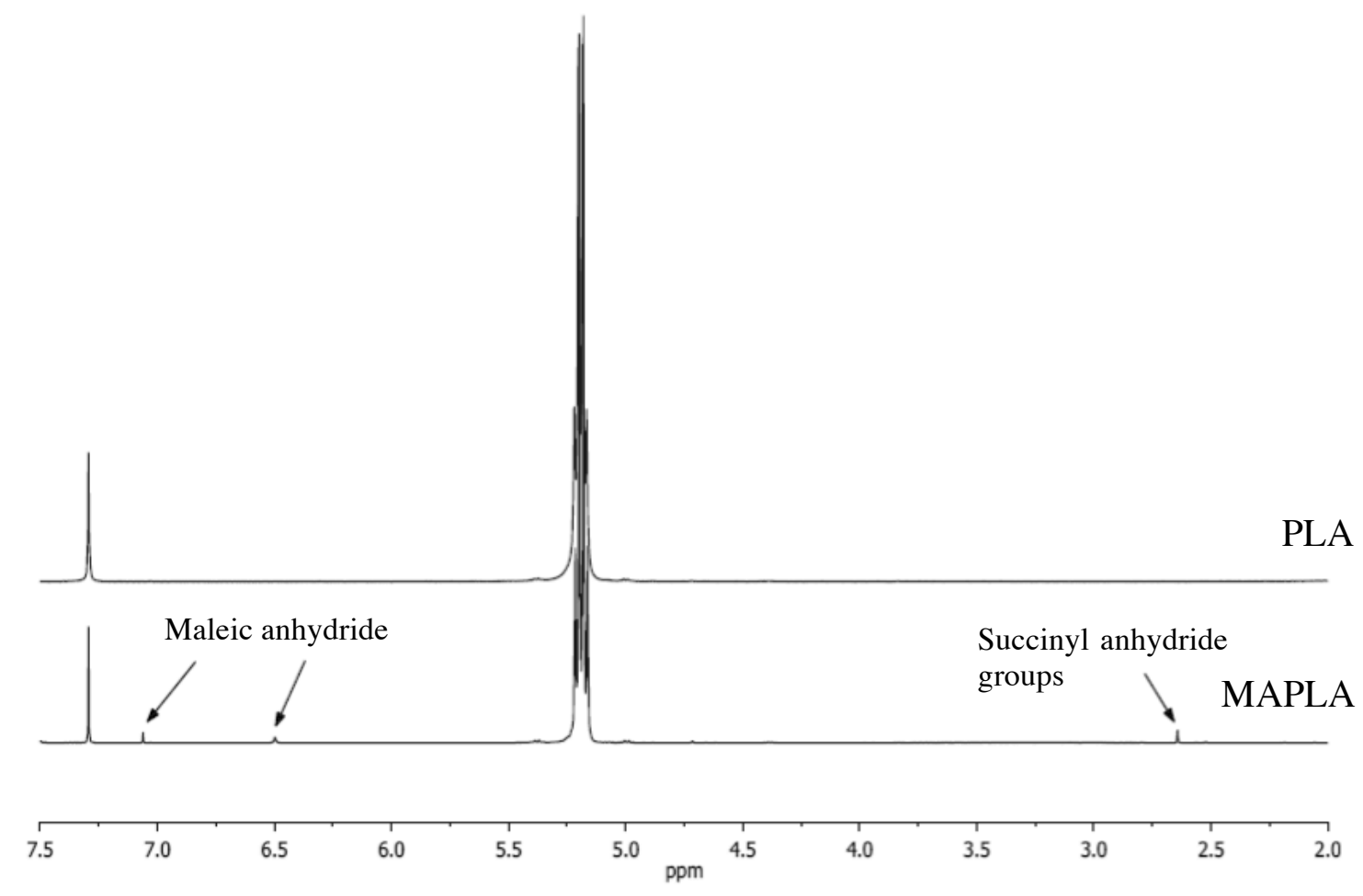

Figure 2 


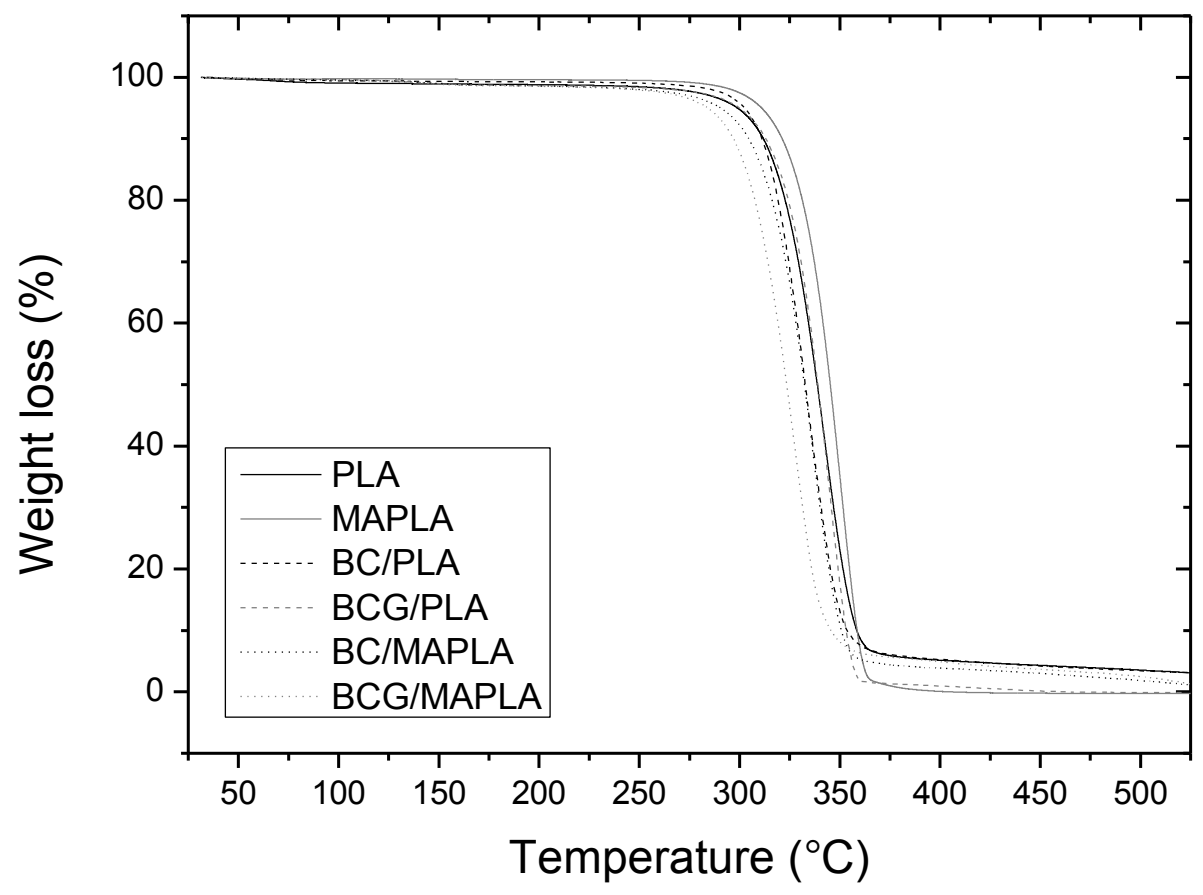

Figure 3 


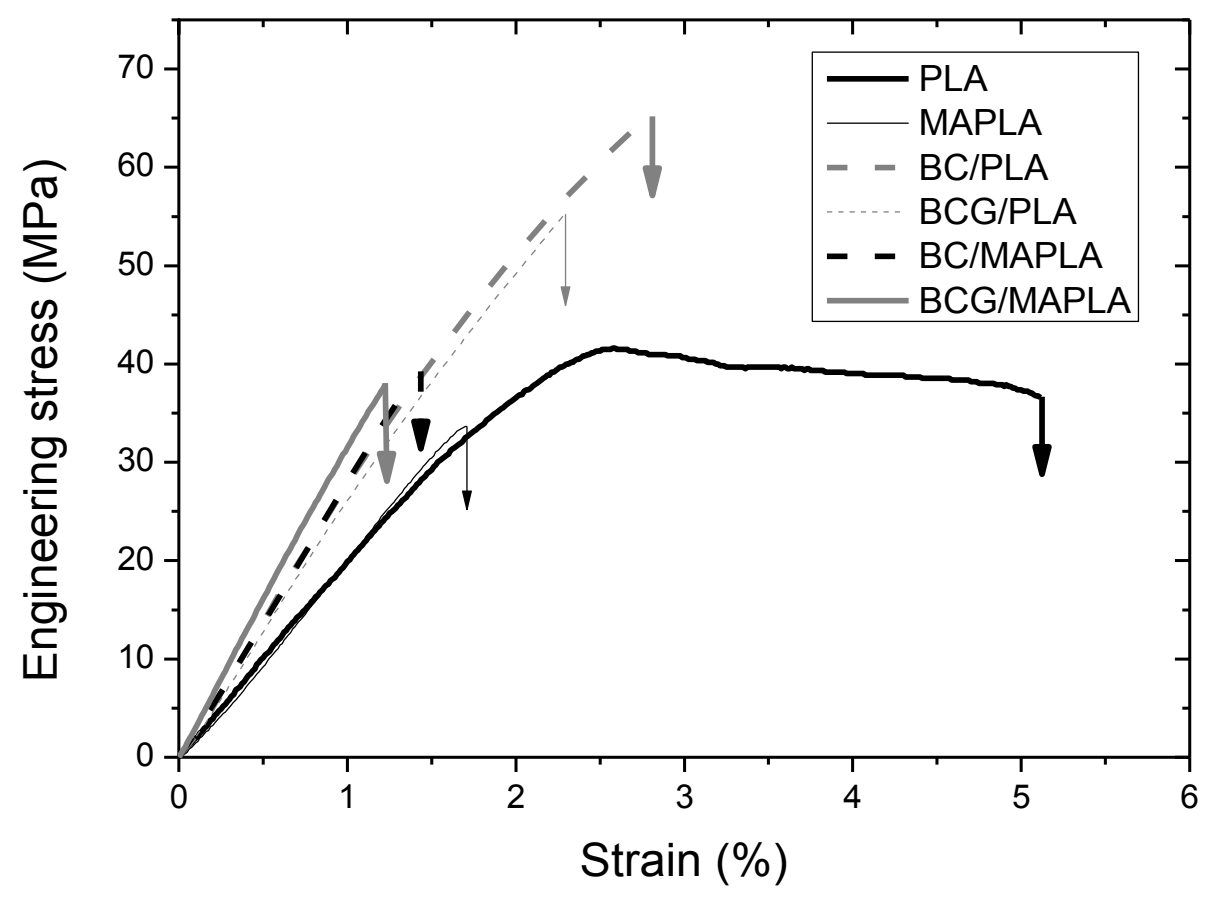

Figure 4 
(a)

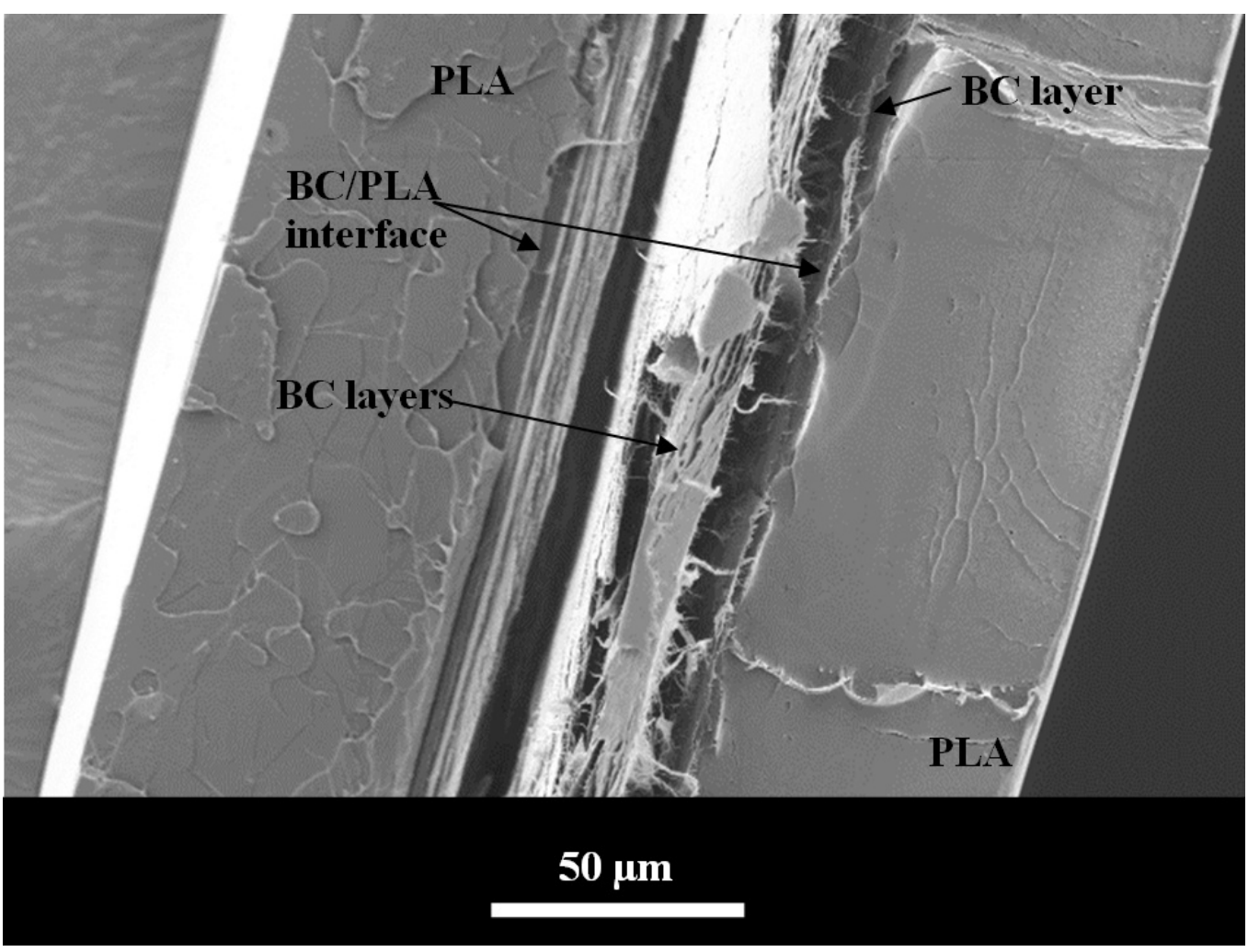

(b)

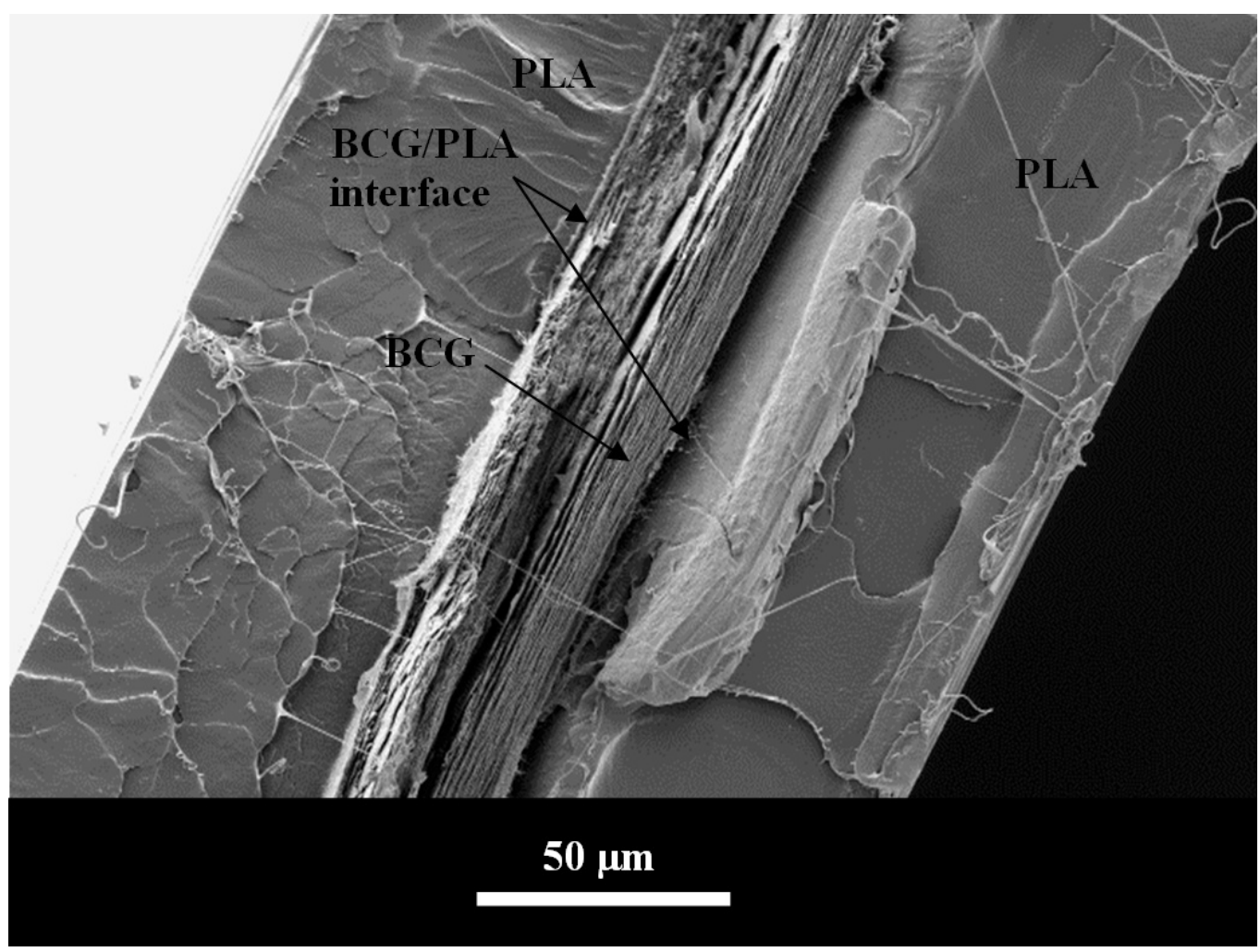


(c)

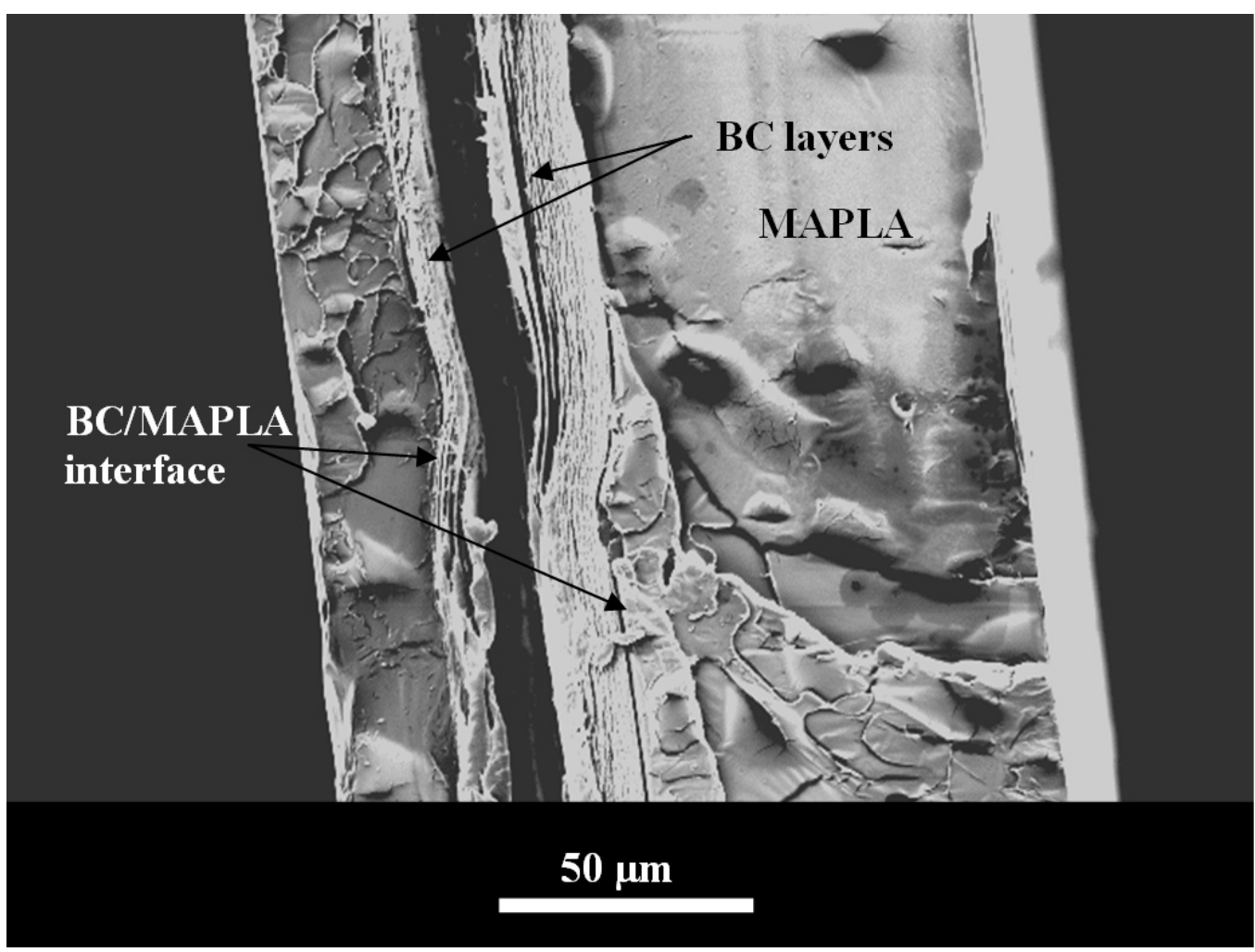

(d)

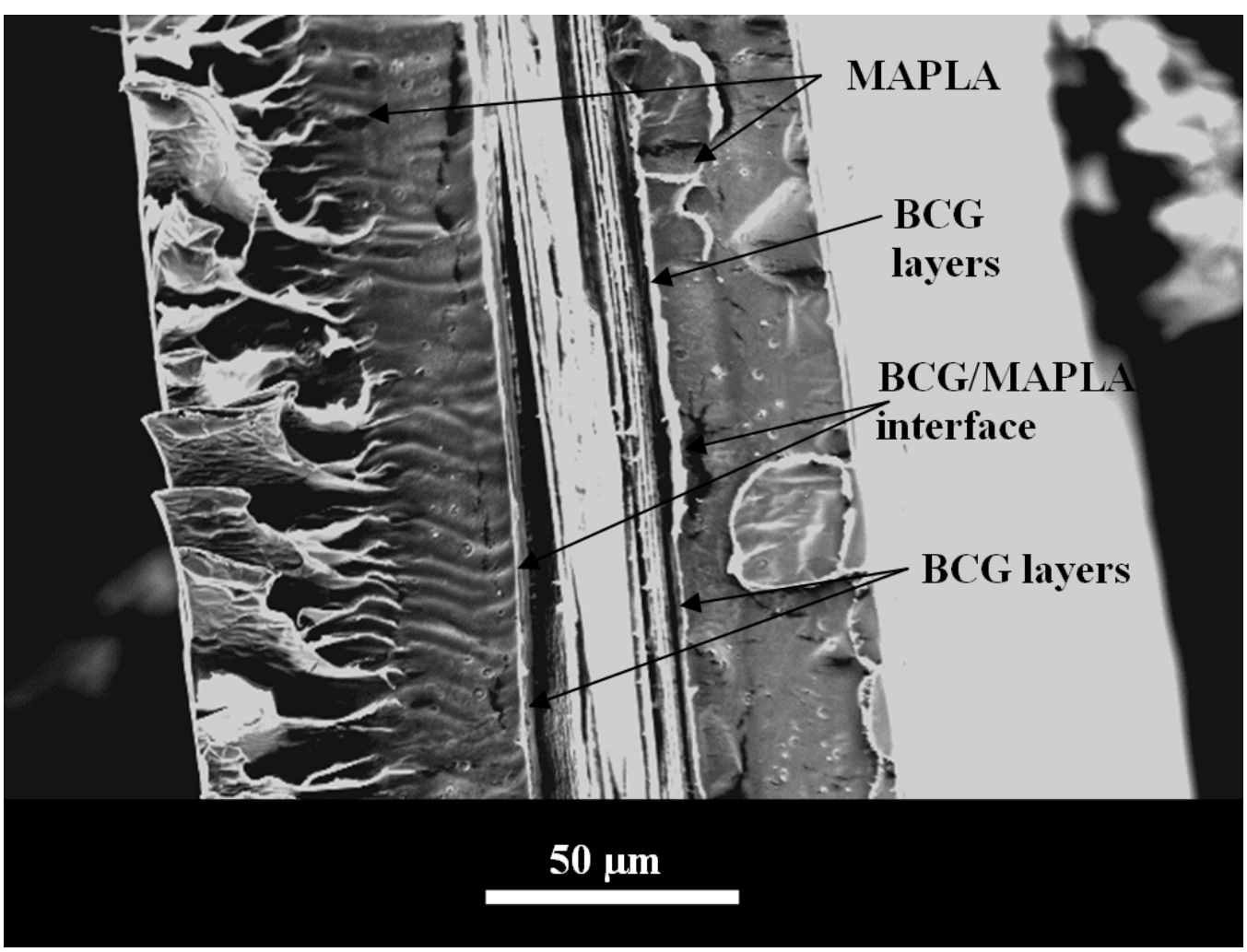

Figure 5 
(a)

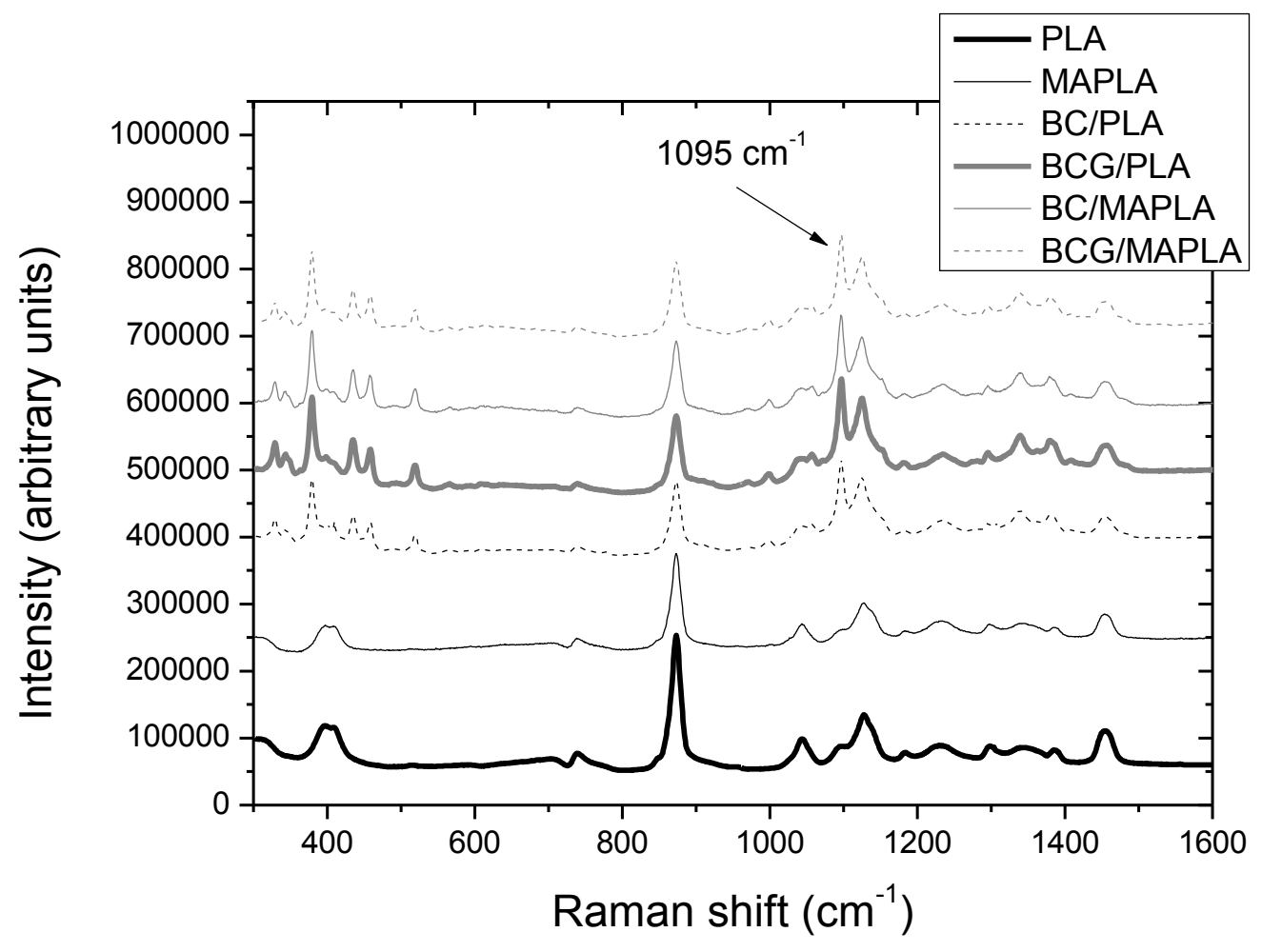

(b)

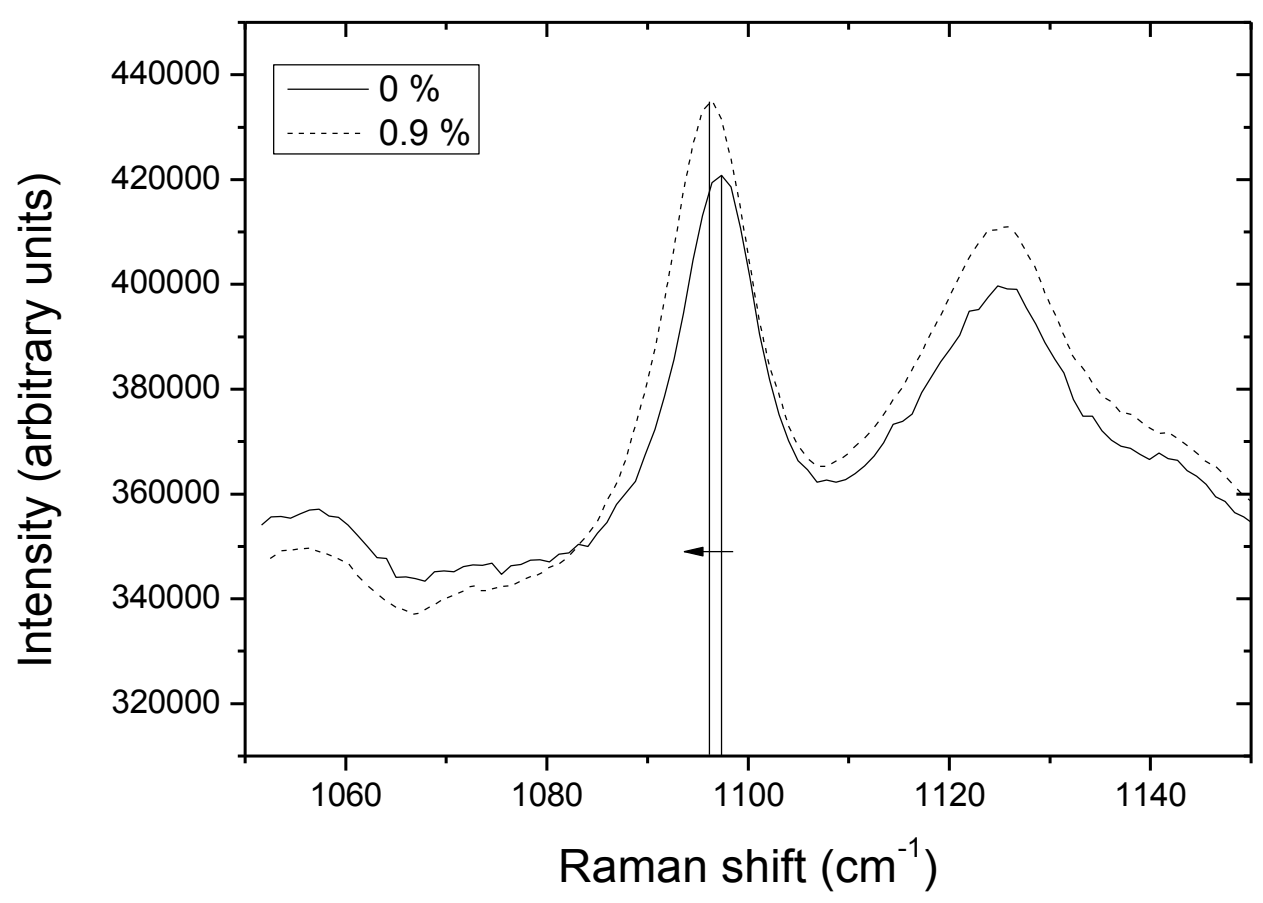

Figure 6 
(a)

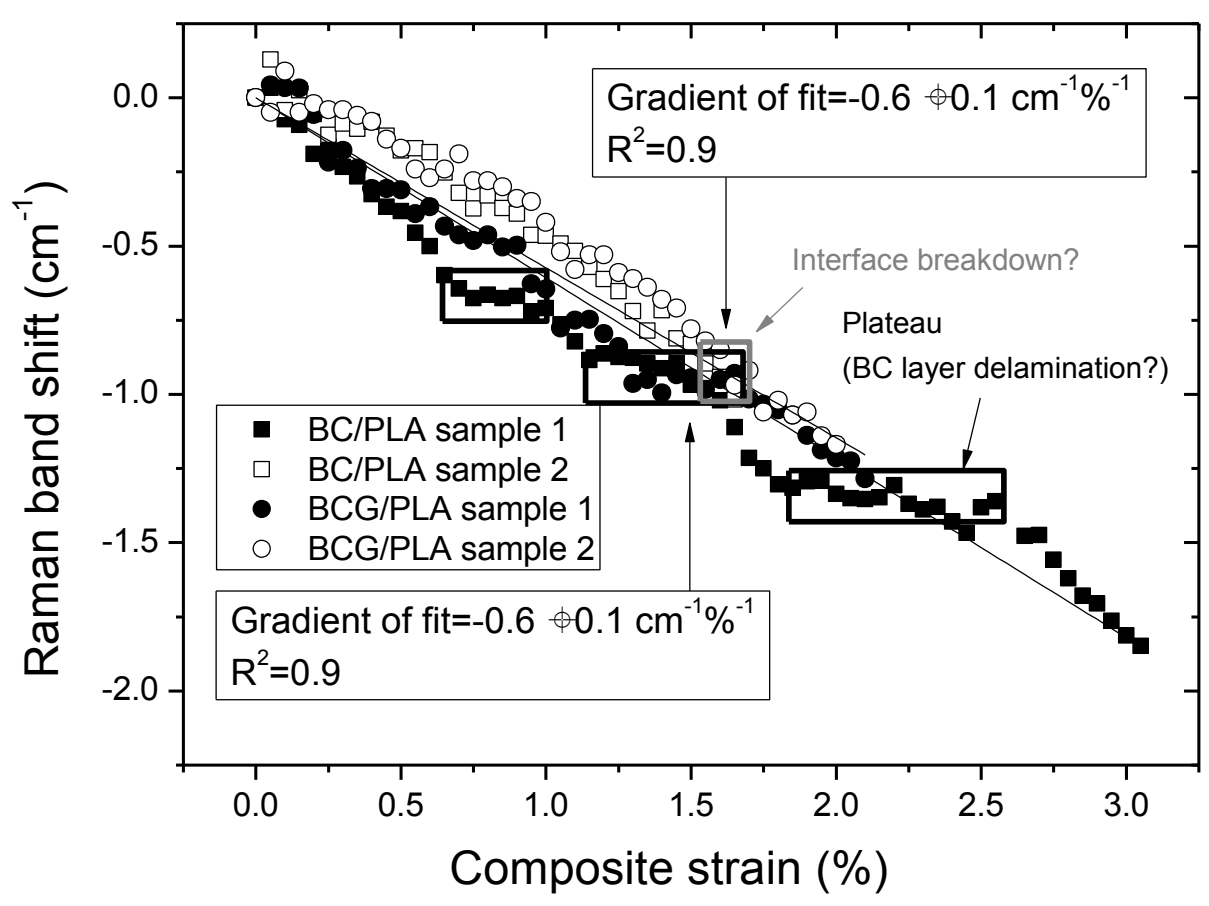

(b)

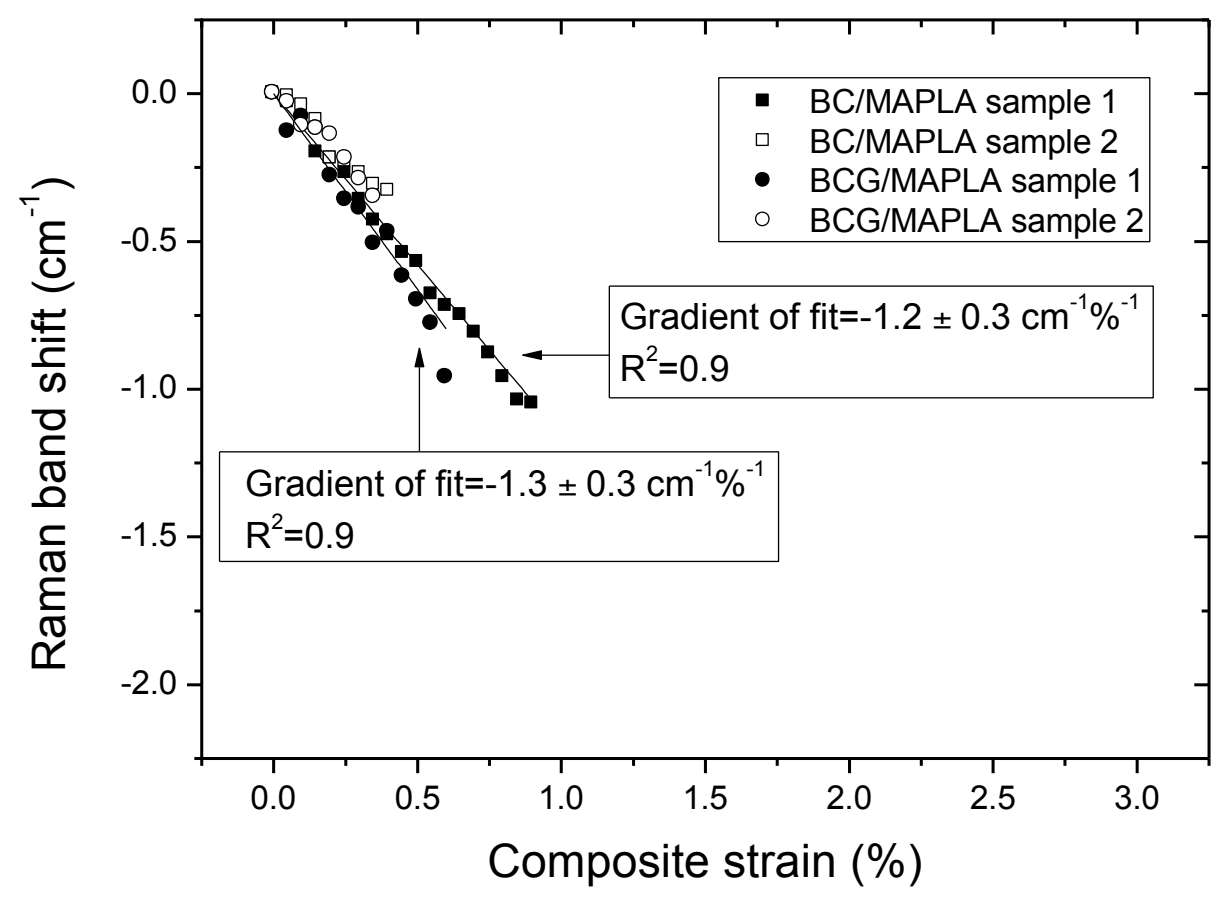

Figure 7 
(a)

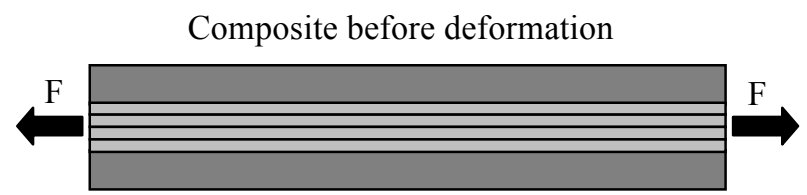

BC layer-to-layer delamination during deformation

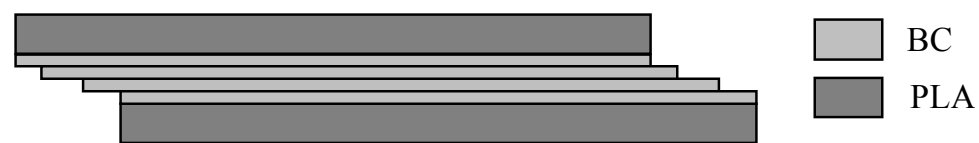

BCG/PLA interface delamination during deformation

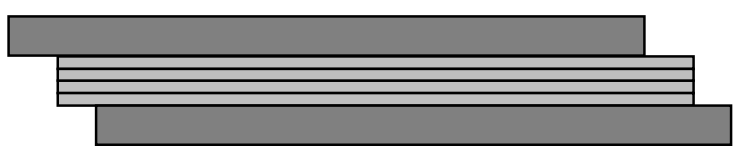

(b)

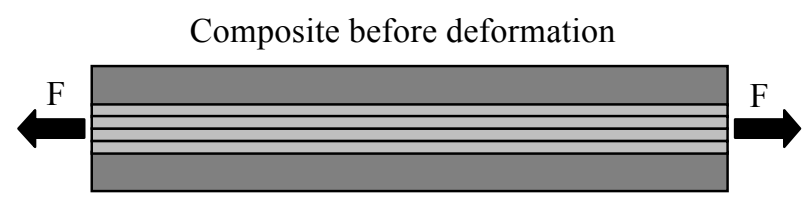

BC layer-to-layer delamination during deformation

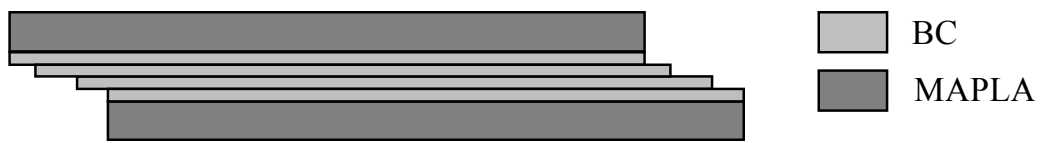

BCG/MAPLA interface delamination during deformation

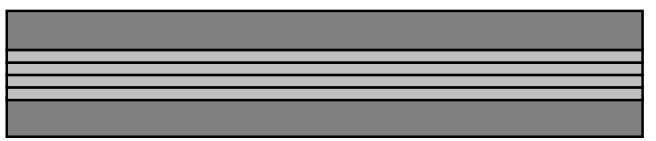

Figure 8 